\title{
Individual differences in social anxiety affect the salience of errors in social contexts
}

\author{
Tyson V. Barker ${ }^{1} \cdot$ Sonya Troller-Renfree $^{1} \cdot$ Daniel S. Pine $^{2} \cdot$ Nathan A. Fox $^{1}$
}

Published online: 13 May 2015

(C) Psychonomic Society, Inc. 2015

\begin{abstract}
The error-related negativity (ERN) is an eventrelated potential that occurs approximately $50 \mathrm{~ms}$ after an erroneous response. The magnitude of the ERN is influenced by contextual factors, such as when errors are made during social evaluation. The ERN is also influenced by individual differences in anxiety, and it is elevated among anxious individuals. However, little research has examined how individual differences in anxiety interact with contextual factors to impact the ERN. Social anxiety involves fear and apprehension of social evaluation. In the present study, we explored how individual differences in social anxiety interact with social contexts to modulate the ERN. The ERN was measured in 43 young adults characterized as being either high or low in social anxiety, while they completed a flanker task in two contexts: alone and during social evaluation. The results revealed a significant interaction between social anxiety and context, such that the ERN was enhanced in a social relative to a nonsocial context only among highly socially anxious individuals. Furthermore, the degree of such enhancement significantly correlated with individual differences in social anxiety. These findings demonstrate that social anxiety is characterized by enhanced neural activity to errors in socialevaluative contexts.
\end{abstract}

Tyson V. Barker

tvbarker@umd.edu

1 Department of Human Development and Quantitative Methodology, University of Maryland, 3304 Benjamin Building, College Park, MD 20742, USA

2 Section on Development and Affective Neuroscience, National Institute of Mental Health (NIMH), Bethesda, MD, USA
Keywords Error-related negativity $\cdot$ Social anxiety $\cdot$ ERP . Positive error

Social anxiety is defined by fear and anxiety of social scrutiny (Rapee \& Heimberg, 1997; Rapee \& Spence, 2004). Unlike other forms of anxiety (e.g., general distress; L. A. Clark \& Watson, 1991), social anxiety is specific to socially threatening contexts (Geen, 1991; Rapee \& Heimberg, 1997; Schlenker \& Leary, 1982). In such contexts, socially anxious, relative to nonanxious, individuals exhibit greater anxious behavior and autonomic arousal, and report greater distress (Beidel, Turner, \& Dancu, 1985; Furlan, DeMartinis, Schweizer, Rickels, \& Lucki, 2001; Levin et al., 1993; Mauss, Wilhelm, \& Gross, 2004). A number of physiological measures display elevated responses during social-evaluative contexts. The startle reflex, a measure of defensive reactivity to threat (Grillon, 2002; Landis, Hunt, \& Strauss, 1939), is elevated during social-evaluative contexts and is related to individual differences in social anxiety (Cornwell, Johnson, Berardi, \& Grillon, 2006), suggesting that social evaluation is particularly anxiogenic on a physiological basis among socially anxious individuals, which results in mobilization and defensive responding to social threats. Findings such as these inform neuroscientific theories of anxiety, since considerable research has delineated the neural correlates of such physiological measures (Grillon, 2002). Social anxiety disorder (SAD), which involves heightened fear of social evaluation, is an extremely common and debilitating disorder affecting over $10 \%$ of the population (Kessler et al., 2005). Generalized anxiety disorder (GAD) and major depressive disorder (MDD) are commonly comorbid among individuals with SAD (Grant et al., 2005). Thus, it is critical to identify the biomarkers specifically associated with social anxiety symptoms to better understand the etiology of SAD. 
Socially anxious individuals demonstrate altered neural patterns including enhanced activation in the anterior cingulate cortex (ACC), particularly when processing socially salient information (Amir, Klumpp, et al., 2005; Lorberbaum et al., 2004). One potential biomarker associated with ACC activity is the error-related negativity (ERN; Dehaene, Posner, \& Tucker, 1994; Holroyd, Dien, \& Coles, 1998; Van Veen \& Carter, 2002), which is a negative deflection in the eventrelated potential (ERP) waveform that occurs approximately $50 \mathrm{~ms}$ after an error (Falkenstein, Hohnsbein, Hoormann, \& Blanke, 1991; Gehring, Goss, Coles, Meyer, \& Donchin, 1993). The ERN is thought to reflect the motivational response to error commission (Hajcak, 2012; Proudfit, Inzlicht, \& Mennin, 2013), given that the ERN is enhanced when errors are perceived as being more distressing and/or threatening (Hajcak \& Foti, 2008; Hajcak, Moser, Yeung, \& Simons, 2005; Riesel, Weinberg, Moran, \& Hajcak, 2013). Contextual factors enhance the ERN, such as in contexts in which accuracy is emphasized over speed (Gehring et al., 1993), when errors are punished (Riesel, Weinberg, Endrass, Kathmann, \& Hajcak, 2012), or when errors incur monetary cost (Ganushchak \& Schiller, 2008; Hajcak et al., 2005). The ERN is also enhanced by social motivational factors, such as when performance is critically evaluated (Hajcak et al., 2005), during interpersonal competition (Van Meel \& Van Heijningen, 2010), or when errors are observed by a peer (Kim et al., 2005). Such contextual factors may be particularly salient among anxious individuals (Riesel et al., 2012). However, it remains unclear how individual differences in social anxiety interact with these social factors to influence the ERN.

A large body of literature links the ERN to individual differences in anxious behavior (see Moser, Moran, Schroder, Donnellan, \& Yeung, 2013, for a review). An enhanced ERN has been observed among individuals with anxiety disorders (Carrasco, Hong, et al., 2013; Endrass, Riesel, Kathmann, \& Buhlmann, 2014; Gehring, Himle, \& Nisenson, 2000; Ladouceur, Dahl, Birmaher, Axelson, \& Ryan, 2006; Weinberg, Olvet, \& Hajcak, 2010), including SAD (Endrass et al., 2014). The ERN is related to subclinical symptoms of anxiety disorders, such as worry (Hajcak, McDonald, \& Simons, 2003a; Moser, Moran, \& Jendrusina, 2012), negative emotionality and affect (Hajcak, McDonald, \& Simons, 2004; Luu, Collins, \& Tucker, 2000), and behavioral inhibition (Amodio, Master, Yee, \& Taylor, 2008; Lahat et al., 2014; McDermott et al., 2009), suggesting that the relation between the ERN and anxiety is driven by personality factors observed among all anxiety disorders (Moser et al., 2012; Proudfit et al., 2013). However, less is known about the relation between the ERN and individual differences in social anxiety.

In addition to the ERN, a number of ERP components are associated with performance and error monitoring. The correct-related negativity $(\mathrm{CRN})$ is a negativity of small magnitude observed on correct motor responses that has a morphology and topography similar to those of the ERN (Ford, 1999; Gehring \& Knight, 2000; Scheffers \& Coles, 2000; Vidal, Burle, Bonnet, Grapperon, \& Hasbroucq, 2003; Vidal, Hasbroucq, Grapperon, \& Bonnet, 2000), but appears to be insensitive to motivational factors (Hajcak et al., 2005; Kim et al., 2005) and individual differences in anxiety (Gehring et al., 2000; Weinberg et al., 2010). A large positive ERP deflection, known as the positive error $(\mathrm{Pe})$, is observed approximately $300 \mathrm{~ms}$ following an error response (Falkenstein et al., 1991), but relations between the Pe and anxiety have been inconsistent, with most studies finding no relation between them (Endrass et al., 2008; Endrass et al., 2014; Hajcak et al., 2003a; Weinberg et al., 2010).

In the present study, we examined the interacting influences of social context and individual differences in social anxiety on the neural correlates of error monitoring (i.e., ERN, CRN, Pe). We recruited young adults who scored at the extremes on symptoms of social anxiety (Fresco et al., 2001; Liebowitz, 1987), and characterized the participants as being either high socially anxious (HSA) or low socially anxious (LSA). We measured the ERN and related components in participants across two different social motivational contexts. In one condition, participants played a computer game and committed errors while alone in a room (i.e., alone condition). In the other condition, participants played the same computer game and committed errors while being observed and evaluated by a peer (i.e., peer condition). We hypothesized that social anxiety would significantly interact with contexts in predicting the magnitude of the ERN, such that the ERN would be enhanced in the peer condition relative to the alone condition only among the HSA individuals. Among LSA individuals, we predicted no differences in the ERNs between conditions. Given the mixed results for the Pe and the CRN, we made no a priori hypotheses for these components.

\section{Method}

\section{Participants}

The final sample included 43 participants ( 22 females, 21 males). Undergraduate students in introductory psychology courses at University of Maryland $(N=792)$ completed the self-report version of the Liebowitz Social Anxiety Scale (LSAS-SR; Fresco et al., 2001; Liebowitz, 1987). The LSAS-SR is a 24-item questionnaire that assesses the degrees of anxiety and avoidance during social interaction and performance situations. Participants rate on a Likert scale from 0 (none) to 3 (severe) how much anxiety they experience in social situations, and from 0 (never) to 3 (usually) how often they avoid these situations. Separate scales for anxiety (Total 
Anxiety) and avoidance (Total Avoidance) are created by summing the relevant items. The LSAS-SR is widely used as a tool to measure the severity of social anxiety in both clinical and nonclinical samples, and it demonstrates excellent psychometric properties (Heimberg et al., 1999). Participants were recruited for the present study if they scored approximately $\pm 1 S D$ on the Total Anxiety scale of the LSAS-SR $(M=24.63, S D=12.8)$. They were excluded for uncorrected visual impairments, inability to provide informed consent, insufficient numbers of errors, or extremely inaccurate task performance, but the study had no other exclusion criteria.

Forty-eight undergraduates ( 26 females, 22 males) were selected for participation on the basis of their LSAS-SR scores. Twenty-five undergraduates (13 females, 12 males) who scored high on LSAS-SR Total Anxiety comprised the HSA group, and 23 undergraduates (12 females, 11 males) who scored low on LSAS-SR Total Anxiety comprised the LSA group. To limit the effect of performance feedback (e.g., feedback to improve accuracy) on the ERN (e.g., Gehring et al., 1993), participants were excluded if their accuracy was below $80 \%$ in any one condition (one participant). Participants were also excluded if fewer than 15 errors were committed (per Larson, Baldwin, Good, \& Fair, 2010) in any one condition (two participants). In addition, two participants were excluded due to technical errors. Therefore, the final sample consisted of 22 (11 female, 11 male) participants in the HSA group and 21 participants (11 female, 10 male) in the LSA group (see Table 1). All participants received course credit for their participation, and the experimenter was blind to the group assignments during experimental testing and data processing.

\section{Measures}

Participants also completed the Penn State Worry Questionnaire (PSWQ; Meyer, Miller, Metzger, \& Borkovec, 1990), a 24-item self-report questionnaire that assesses trait aspects of anxious apprehension (i.e., worry), which is closely aligned to general anxiety symptoms characteristic of GAD. The PSWQ has demonstrated high internal reliability in normative and clinical populations and has been known to accurately distinguish the construct of worry from other constructs of anxiety and depression (Brown, Antony, \& Barlow, 1992; Davey, 1993; Gillis, Haaga, \& Ford, 1995). Participants also completed the Beck Depression Inventory-II (BDI-II; Beck et al., 1996), a widely used measure of depression that assesses the presence and severity of depressive symptomology across 21 items. The BDI-II has been utilized extensively in normative samples to assess individual differences in depressive symptoms (Bumberry, Oliver, \& McClure, 1978).

\section{Task and materials}

An adapted arrow version of the flanker task (Eriksen \& Eriksen, 1974) was administered using the E-Prime software (Psychology Software Tools, Inc., Sharpsburg, PA). On each trial, participants viewed five horizontal arrowheads. On half of the trials the arrowheads were congruent $(<<<<<,>>>>>)$, and on the other half the arrowheads were incongruent $(<<><<,>><>>)$. The order of presentation of the arrowheads was random. The stimuli were approximately $13.8 \mathrm{~cm}$ in height and $2.6 \mathrm{~cm}$ in width, and all were presented for $200 \mathrm{~ms}$. An intertrial interval that varied randomly from 700 to $1,100 \mathrm{~ms}$ either followed the response or began $800 \mathrm{~ms}$ after stimulus onset (whichever occurred first).

\section{Procedure}

Upon arrival at the laboratory, participants were greeted and provided consent to the experimenter, and then they were seated next to a gender-matched undergraduate who was a confederate and who acted as a participant throughout the study. The experimenter informed both the participant and the confederate that they were participating in the same study, and both were given questionnaires to complete. After completing all questionnaires, participants were informed that they would be completing a computer game twice, each time in a

Table 1 Descriptive statistics for the low socially anxious and high socially anxious groups, and scores among each group for symptoms of social anxiety, general anxiety, and depression

\begin{tabular}{lll}
\hline & Low Socially Anxious & High Socially Anxious \\
\hline$N$ & $21(11$ female) & $22(11$ female) \\
Age (years) & $19.51(1.0)$ & $19.77(1.2)$ \\
Liebowitz Social Anxiety Scale (Total Score) & $20.76(9.0)$ & $76.41(11.3)$ \\
Liebowitz Social Anxiety Scale (Total Anxiety) & $9.76(3.3)$ & $41.68(5.6)$ \\
Beck Depression Inventory & $4.48(5.3)$ & $10.23(7.4)$ \\
Penn State Worry Questionnaire & $42.33(12.9)$ & $58.59(10.5)$ \\
\hline
\end{tabular}

Parentheses in the bottom five rows indicate standard deviations 
different context. In one of the contexts, the participant and the confederate would complete the game alone in separate rooms (i.e., alone condition). In the other context, the participant and confederate would be studied in the same room, where one participant would be the "player" and the other participant would be the "observer" (i.e., peer condition). To determine who would be the player and the observer in the peer condition, participants drew numbers out of a hat (the actual participant always drew the number to be the player). After the experimenter explained both conditions, the confederate was led out of the room by a research assistant, and the experimenter went on to explain the instructions of the computer task to the participant. The order of the conditions was counterbalanced across participants.

During the peer condition, the confederate was taken into the room after the participant had been prepped for electroencephalogram (EEG) collection. The confederate was instructed to sit at a table with a computer that was at a $90^{\circ}$ angle from the participant. When both the participant and the experimenter were seated in the room, the experimenter explained that the confederate would see the performance of the participant on the confederate's own computer screen (i.e., reaction times and accuracy). In addition, the confederate was given a clipboard and told to mark down every error that the participant made while completing the task. During the alone condition, the participant was told that the confederate was playing the computer game in an adjacent room.

Participants were seated with a hand-held button box approximately $30 \mathrm{in}$. from the monitor and were instructed to press the right button when the middle arrow was pointing to the right, and to press the left button when the middle arrow was pointing to the left. Participants performed a practice block of 30 trials. The experimental task consisted of eight blocks of 52 trials (416 trials total). Two participants (one from the HSA and one from the LSA group) completed 48 trials per block, for a total of 386 trials. Prior to beginning the task, participants were told to be as fast and accurate as possible. After each block, they received a short break and feedback about their performance (Weinberg et al., 2010). If performance was $75 \%$ or below, the message "Please be more accurate" was displayed. If performance was above $90 \%$, participants received the message "Please respond faster." No feedback was given for performance between $75 \%$ and $90 \%$.

\section{EEG data collection and analysis}

Continuous EEG was recorded using a 128-channel Geodesic Sensor Net and sampled at $250 \mathrm{~Hz}$ using the EGI software (Electrical Geodesic, Inc, Eugene, OR). Before data collection, all electrode impedances were reduced to below $50 \mathrm{k} \Omega$. All electrodes were referenced online to $\mathrm{Cz}$ and re-referenced to an average reference offline. The data were filtered offline using a digital band-pass FIR filter from 0.3 to $30 \mathrm{~Hz}$.

Reponses-locked trials were segmented separately for error and correct trials from $400 \mathrm{~ms}$ before the response to $800 \mathrm{~ms}$ after the response (1,200 ms total). Eye blinks were removed from the segmented waveforms using independent component analysis (ICA) performed by the ERP PCA Toolkit (Delorme \& Makeig, 2004; Dien, 2010). Individual blinks were identified for each participant to create an average blink topography from all respondents. The ICA components for each participant that correlated at .9 or above with the averaged blink topography and/or with the ERP PCA Toolkit-supplied blink topography were removed. Next, a semi-automated procedure was utilized for artifact rejection and detection. Channels were marked bad if the fast average amplitude exceeded $100 \mu \mathrm{V}$ or if the difference between a channel and the neighboring channels was greater than $40 \mu \mathrm{V}$ for an individual segment. Channels were marked globally bad if the correlation between neighboring channels was less than .30 or if the channel was bad on greater than $20 \%$ of trials. Trials were marked bad if more than $10 \%$ of the channels were determined to be bad (alone condition, $1.7 \%$ of trials; peer condition, $1.8 \%$ of trials). Bad channels on the remaining good trials were replaced using spherical spline interpolation (Perrin et al., 1989, 1990). Individual error trials were visually inspected for any remaining artifacts. All visual detection of artifacts was done blind to group membership. There were no differences in the numbers of artifact-free error trials for the HSA group $(M=52.18, S D=11.6)$ or for the LSA group $(M=$ $50.86, S D=14.4)$ in the alone condition, $t(41)=0.33, p=$ .74 , nor any differences between groups in the peer condition (HSA: $M=48.09, S D=14.0$; LSA: $M=50.67, S D=12.2$ ), $t(41)=0.64, p=.52$.

All correct and error trials were separately averaged for each participant and then were baseline corrected to the average activity from $400 \mathrm{~ms}$ before the response to $200 \mathrm{~ms}$ before the response. Channels were collapsed to create channel groups for each component by averaging activity over a group of channels, in order to reduce multiple testing for independent channels, and thus reduce Type I errors. The ERN and $\mathrm{CRN}$ were evaluated as the average activity at four frontocentral electrodes at the midline (6 [FCz], 7, 107, and $\mathrm{Cz}$ ), where the ERN was maximally negative. The Pe and correct Pe (i.e., Pe on correct trials) were evaluated as the average activity at seven centro-parietal electrodes $(\mathrm{Cz}, 31,54,55$ [PCz], 62 [Pz], 79, and 80), where the Pe was maximally positive. The ERN and CRN amplitudes were extracted as the mean activity $0-100 \mathrm{~ms}$ following the response for error and correct trials, respectively. The Pe and correct Pe amplitudes were extracted as the average activity $200-400 \mathrm{~ms}$ following the response for error and correct trials, respectively. To examine brain activity specific to errors, a difference wave was created by subtracting the brain activity on correct trials 
from the brain activity on error trials for the ERN (i.e., ERN CRN; $\triangle \mathrm{ERN}$ ). Similarly, a change score was calculated for the Pe by subtracting the correct Pe from the Pe $(\Delta \mathrm{Pe})$. In addition, in order to examine the change in neural activity across conditions, the neural activity from the alone condition was subtracted from the neural activity in the peer condition for the ERP measures of interest (e.g., Peer ERN - Alone ERN, Peer $\triangle E R N$ - Alone $\triangle E R N)$.

Trials with reaction times faster than $200 \mathrm{~ms}$ and slower than $800 \mathrm{~ms}$ were removed from the analysis (alone condition, $1.1 \%$ trials; peer condition, $0.8 \%$ trials). The numbers of trials excluded due to extreme reaction times were not different between groups in the alone condition, $t(41)=1.68, p=$ .10 , or in the peer condition, $t(41)=1.37, p=.18$. Accuracy was calculated as the number of correct trials divided by the total number of trials with a response. Reaction times were averaged separately for correct trials and error trials for each participant in each condition.

\section{Data analysis}

To investigate differences in behavioral performance (i.e., reaction time, accuracy) between groups and conditions, mixedmodel analyses of variance (ANOVAs) were conducted with group (HSA, LSA) as the between-subjects factor and condition (alone, peer) and response (correct, incorrect) as the within-subjects factors. Similarly, to examine differences in the ERP measures, separate 2 (group) $\times 2$ (condition) $\times 2$ (response) mixed-model ANOVAs were conducted for the ERN and the Pe. For the $\triangle E R N$ (i.e., ERN $-C R N$ ) and the $\triangle \mathrm{Pe}$ (i.e., $\mathrm{Pe}-$ correct $\mathrm{Pe}$ ), separate 2 (group) $\times 2$ (condition) mixed-model ANOVAs were conducted. Degrees of freedom were adjusted using the Greenhouse-Geisser method for all within-subjects comparisons to reduce Type I errors. Significant group interaction effects were explored by conducting follow-up ANOVAs and paired-sample $t$ tests separately for each group.

Next, the relation between the ERP measures and selfreport measures was explored. First, a one-way multivariate analysis of variance (MANOVA) was conducted for the PSWQ, LSAS-SR, and BDI to explore differences in social anxiety, general anxiety, and depressive symptoms between the HSA and LSA groups. Second, the Pearson correlation coefficient was utilized to examine the relation between the ERP measures and self-report questionnaires of anxiety and depression. Next, correlations were calculated to examine the relations between changes in the ERP measures across the alone and peer conditions (e.g., Peer ERN - Alone ERN) and the self-report measures. Finally, to determine the unique contributions of the different types of anxiety in predicting the ERN, a multiple regression model was conducted with LSAS social anxiety and PSWQ general anxiety as predictors and the change in $\triangle E R N$ across conditions as the outcome variable. Significance was evaluated at the .05 level for all statistical analyses.

\section{Results}

Table 2 displays the reaction times and accuracies across the peer and alone conditions for the HSA and LSA groups. Analysis of the reaction times demonstrated a main effect of response, in which participants across both groups and conditions exhibited faster reaction times on error trials than on correct trials, $F(1,41)=768.45, p<.001, \eta^{2}=.95$. No other main or interaction effects reached significance. For the analysis of accuracy, no main or interaction effects were significant $(p s>.10)$.

Figure 1 presents the ERP waveforms across the alone and peer conditions for the HSA and LSA groups at the frontocentral electrode grouping (where the ERN was maximal) and the centro-parietal electrode grouping (where the Pe was maximal). Figure 2 presents the scalp topographies of the ERN for the LSA and HSA groups across each condition. The means for all ERP measures in each condition for the HSA and LSA groups are presented in Table 2 . Analysis of the neural activity during error responses (i.e., ERN) and correct responses (i.e., CRN) indicated a main effect of response, in which the ERN was significantly larger (i.e., more negative) than the CRN across both conditions and groups, $F(1,41)=126.91, p<$ $.001, \eta^{2}=.76$. However, this main effect was qualified by a significant three-way (group $\times$ condition $\times$ response) interaction, $F(1,41)=4.86, p=.033, \eta^{2}=.11$, suggesting that the HSA and LSA groups demonstrated different patterns of the ERN and CRN across conditions. ${ }^{1}$ To explore this interaction, separate 2 (condition) $\times 2$ (response) ANOVAs were conducted for each anxiety group. For the LSA group, we found no differences in the ERN or the CRN between conditions, $F(1$, $20)=0.10, p=.76, \eta^{2}=.01$, nor any interaction between the ERN and the CRN, $F(1,20)=0.60, p=.54, \eta^{2}=.03$. However, for the HSA group, a main effect of condition emerged, suggesting enhanced neural activity in the peer condition relative to the alone condition, $F(1,21)=8.01, p=.01$, $\eta^{2}=.28$. This was qualified by a condition $\times$ response interaction, $F(1,21)=5.09, p=.035, \eta^{2}=.20$. Multiple paired-

\footnotetext{
${ }^{1}$ To examine the influence of extreme values on these ANOVA results, the relatively conservative robust ANOVA procedure (Keselman, Wilcox, \& Lix, 2003) was utilized in the ERP Toolkit as part of a secondary analysis (Dien, 2010). The omnibus robust ANOVA revealed a main effect of response, $\mathrm{T}_{\mathrm{WJt}} / \mathrm{c}(1.0,32.6)=123.71, p<.001$. This was qualified by a condition $\times$ response $\times$ anxiety group interaction approaching significance, $\mathrm{T}_{\mathrm{WJt}} / \mathrm{c}(1.0,36.7)=3.69, p=.059$. Follow-up analyses utilizing the robust ANOVA procedure also yielded similar results.
} 
Table 2 Means for behavioral performance and event-related potential (ERP) measures (standard deviationsin parentheses) for the high socially anxious group $(n=22)$ and the low socially anxious group $(n=21)$ in the peer and alone conditions

\begin{tabular}{|c|c|c|c|c|}
\hline & \multicolumn{2}{|c|}{ Low Socially Anxious } & \multicolumn{2}{|c|}{ High Socially Anxious } \\
\hline & Peer & Alone & Peer & Alone \\
\hline \multicolumn{5}{|l|}{ Behavior Measures } \\
\hline Error reaction time $(\mathrm{ms})$ & $295.01(21.4)$ & $300.26(21.6)$ & $296.13(31.9)$ & $293.61(29.2)$ \\
\hline Correct reaction time (ms) & $350.35(31.0)$ & $356.92(25.5)$ & $346.47(35.5)$ & $344.21(35.7)$ \\
\hline Accuracy $(\%)$ & $87.45(3.13)$ & $87.32(3.5)$ & $87.87(3.5)$ & $86.76(2.6)$ \\
\hline \multicolumn{5}{|l|}{ ERPs $(\mu \mathrm{V})$} \\
\hline ERN & $-0.88(3.3)$ & $-0.90(3.6)$ & $-2.04(3.5)^{*}$ & $-1.19(3.2)^{*}$ \\
\hline CRN & $4.57(3.3)$ & $4.80(3.1)$ & $4.77(2.8)$ & $4.83(2.6)$ \\
\hline$\triangle \mathrm{ERN}$ & $-5.45(3.8)$ & $-5.69(3.8)$ & $-6.81(3.6)^{*}$ & $-6.0(3.0)^{*}$ \\
\hline $\mathrm{Pe}$ & $6.74(3.6)$ & $7.05(3.5)$ & $6.82(4.0)$ & $6.13(3.5)$ \\
\hline Correct Pe & $0.25(1.5)$ & $0.60(1.4)$ & $0.61(2.0)$ & $0.56(1.7)$ \\
\hline$\Delta \mathrm{Pe}$ & $6.49(2.8)$ & $6.44(2.8)$ & $6.21(3.0)$ & $5.57(2.7)$ \\
\hline
\end{tabular}

${ }^{*} p<.05$, indicating a difference between the peer condition and the alone condition within each group

samples $t$ tests revealed that this interaction was primarily driven by enhancements of the ERN in the peer condition $(M=-2.04, S D=3.4)$ as compared to the alone condition
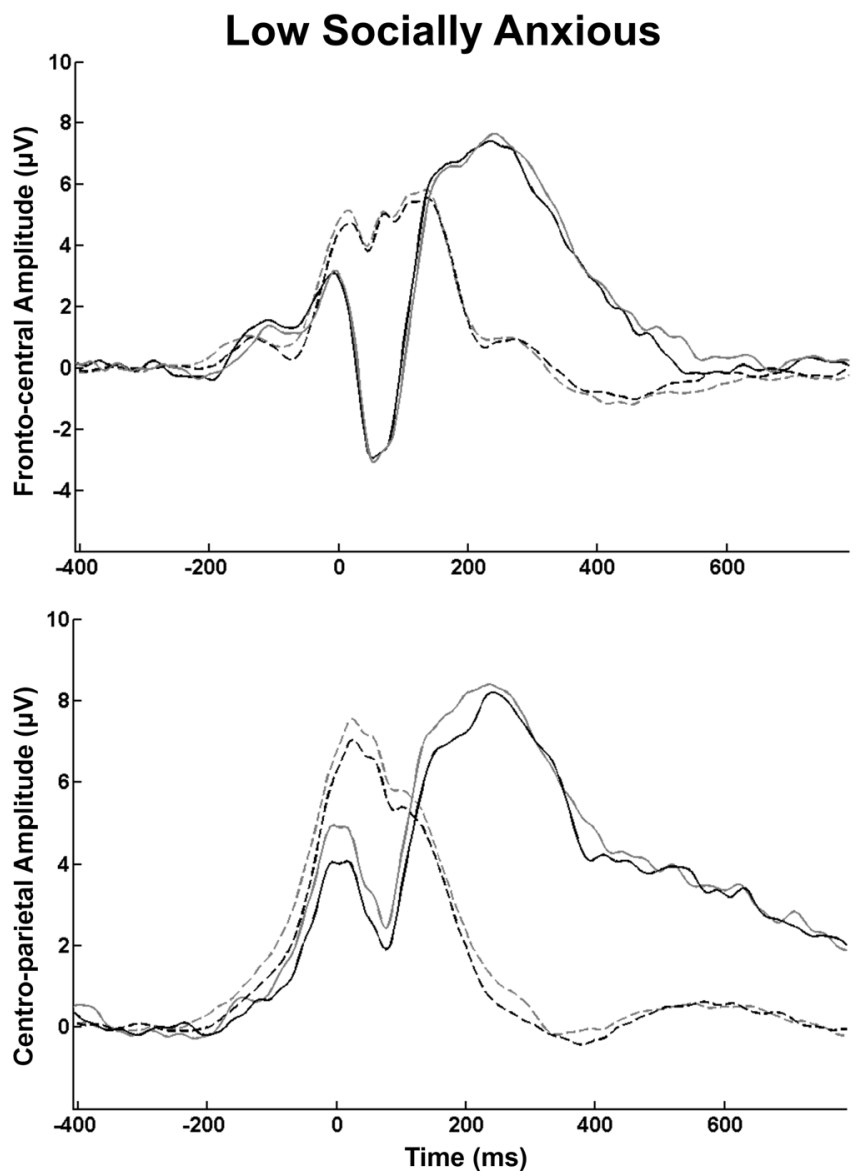

Fig. 1 Response-locked event-related potential waveforms on correct and error responses in the peer and alone conditions for the low socially anxious (left) and high socially anxious (right) groups. The top row is the
$(M=-1.19, S D=3.2)$ for the HSA group, $t(21)=3.57, p=$ $.002, d=0.85$ (see Fig. 2 for the scalp topographies of the ERN for the HSA group). No differences in the CRN were

\section{High Socially Anxious}
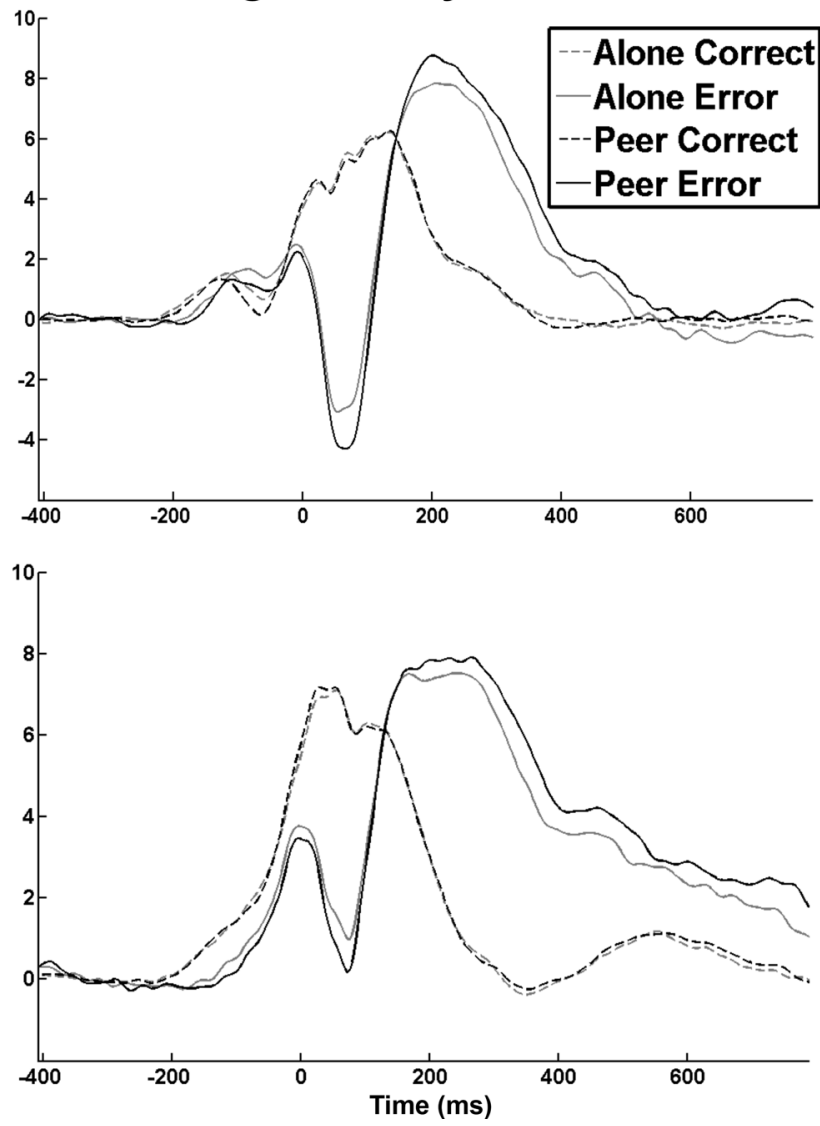

fronto-central electrode grouping, where the error-related negativity was maximal. The bottom row is the centro-parietal electrode grouping, where the positive error was maximal 


\section{Low Socially Anxious High Socially Anxious}

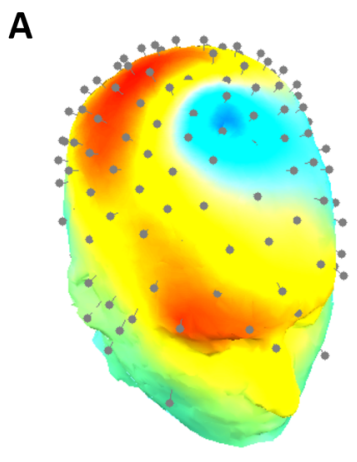

B

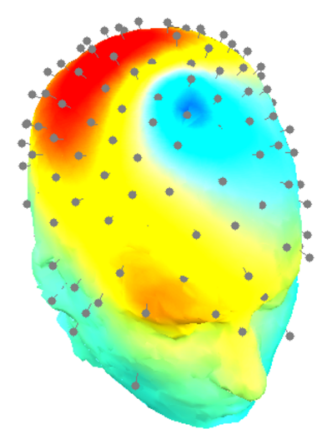

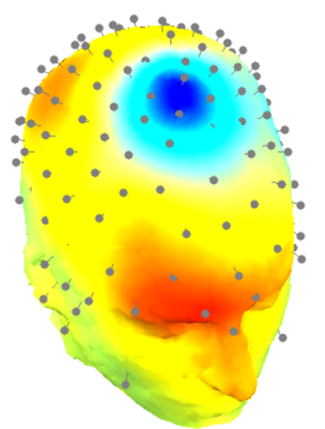
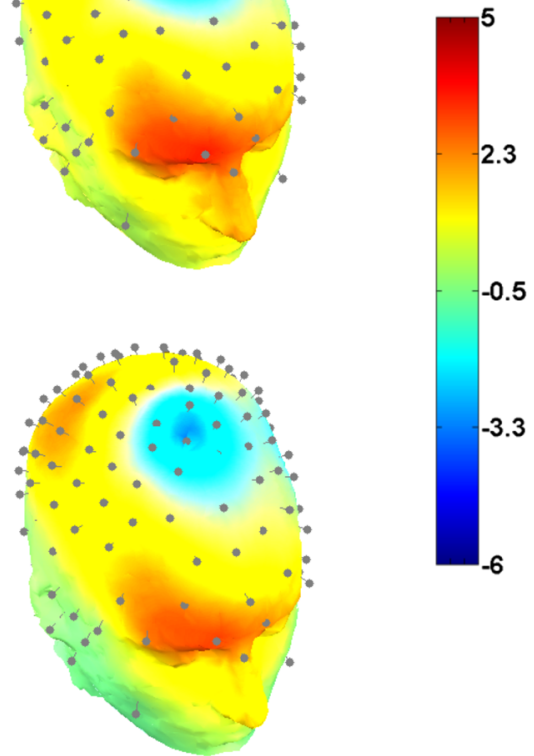

Fig. 2 Scalp topographies of the error-related negativity for the low socially anxious group (left) and the high socially anxious group (right) during the peer condition (top) and the alone condition (bottom) at $68 \mathrm{~ms}$ postresponse

observed between the peer and alone conditions for the HSA group, $t(21)=0.23, p=.82, d=0.04$.

In the analysis of the $\triangle E R N$, we observed a significant condition $\times$ group interaction, $F(1,41)=4.86, p=.033, \eta^{2}$ $=.11$. Separate follow-up paired-samples $t$ tests for each group revealed that the HSA group demonstrated a larger $\triangle E R N$ in the peer condition $(M=-6.81, S D=3.6)$ than in the alone condition $(M=-6.01, S D=3.0), t(21)=2.26, p=.035, d=$ 0.56 , whereas no differences in the $\triangle E R N$ between conditions were apparent for the LSA group, $t(20)=0.78, p=.45, d=$ 0.17 .

For the Pe, the repeated measures ANOVA for the centroparietal electrode grouping (where the Pe was maximal) indicated a main effect of response, in which the Pe on error trials was significantly larger than the Pe on correct trials across both conditions and groups, $F(1,41)=222.28, p<.001, \eta^{2}$ $=.84$. This effect was qualified by a significant condition $\times$ group interaction, $F(1,41)=4.13, p=.049, \eta^{2}=.09$. However, follow-up ANOVAs indicated no main effects of condition for the HSA group, $F(1,21)=2.96, p=.10, \eta^{2}=$ .12 , or the LSA group, $F(1,20)=1.49, p=.24, \eta^{2}=.07$.

Table 1 displays the means and standard deviations for the self-report questionnaires. The one-way MANOVA revealed a significant multivariate main effect of group, suggesting that the HSA group reported more social anxiety (LSAS-SR), general anxiety (PSWQ), and depressive symptoms (BDI) than the LSA group, Wilks's $\lambda=.114, F(3,39)=101.30, p<.001$, $\eta^{2}=.88$. As expected, there were significant correlations among all of the questionnaire measures. Social anxiety symptoms were positively related to both symptoms of general anxiety, $r(41)=.60, p<.001$, and depressive symptoms, $r(41)=.40 p=.008$. General anxiety symptoms were also positively related to depressive symptoms, $r(41)=.45 p=$ .002 .

Table 3 displays the Pearson correlation coefficients between the ERP measures and the self-report questionnaires. Across the whole sample, ERP measures from both conditions were unrelated to the measures of social anxiety, general anxiety, and depression ( $p$ s $>$.18). However, changes in the $\triangle \mathrm{ERN}$ across conditions (Peer $\Delta \mathrm{ERN}-$ Alone $\Delta \mathrm{ERN}$ ) were negatively correlated with social anxiety symptoms, such that a larger $\triangle E R N$ in the peer condition than in the alone condition was related to more social anxiety symptoms, $r(41)=$ $-.33, p=.030$ (see Fig. 3). ${ }^{2}$ The change in the $\Delta$ ERN across conditions was also marginally associated with general anxiety symptoms, $r(41)=-.30, p=.051$. The regression model revealed that neither LSAS social anxiety nor PSWQ general anxiety uniquely predicted the $\triangle \mathrm{ERN}$ across conditions when

\footnotetext{
${ }^{2}$ Although several data points in the bivariate correlation were influential observations, analysis of the residuals revealed no outliers.
} 
Table 3 Pearson correlation coefficient for event-related potential (ERP) and self-report measures

\begin{tabular}{lccc}
\hline & LSAS-SR & PSWQ & BDI-II \\
\hline Alone & & & \\
ERN & .01 & -.15 & -.07 \\
$\mathrm{CRN}$ & .03 & -.03 & .05 \\
$\Delta \mathrm{ERN}$ & -.03 & -.12 & -.12 \\
$\mathrm{Pe}$ & -.13 & -.07 & -.18 \\
Correct Pe & -.03 & -.07 & -.09 \\
$\Delta \mathrm{Pe}$ & -.15 & -.05 & -.19 \\
Social Effect (Peer - Alone) & & \\
ERN & $-.30^{\dagger}$ & -.17 & -.05 \\
$\Delta \mathrm{ERN}$ & $-.33^{*}$ & $-.30^{\dagger}$ & -.05 \\
Pe & .25 & .21 & -.07 \\
$\Delta \mathrm{Pe}$ & .17 & $.31^{*}$ & .01 \\
\hline
\end{tabular}

The top rows represent ERPs during the alone condition. The bottom rows represent the differences in ERP measures between the alone and peer conditions (i.e., Peer - Alone). ${ }^{*} p<.05,{ }^{\dagger} p<.10$

both scales were included in the same model $(p s>.20)$. For the $\Delta \mathrm{Pe}$, changes across conditions (Peer $\Delta \mathrm{Pe}-$ Alone $\Delta \mathrm{Pe}$ ) were positively correlated with general anxiety symptoms, $r(41)=.31, p=.047$.

\section{Discussion}

The goal of the present study was to examine error-related brain activity in socially anxious individuals across social and nonsocial contexts. We explored whether highly socially anxious individuals exhibit greater enhancements of the ERN in a social than in a nonsocial context, as compared to low socially anxious individuals. As was hypothesized, we found a significant interaction between social anxiety and context, such that the ERN and the $\triangle E R N$ were enhanced in the social context as compared to the nonsocial context only among high socially anxious individuals. Furthermore, the degree to which the ERN was enhanced in social contexts significantly correlated with social anxiety symptoms. These findings suggest that social context uniquely modulates the ERN in socially anxious individuals.

Current theory suggests that the ERN represents a defensive response to error commission (Hajcak \& Foti, 2008; Proudfit et al., 2013). Errors are aversive events that cause a range of physiological changes associated with enhanced vigilance to threat, such as heart rate deceleration (Hajcak, McDonald, \& Simons, 2003b), elevated skin conductance (Hajcak et al., 2003b), pupil dilation (Critchley, Tang, Glaser, Butterworth, \& Dolan, 2005), and potentiation of the startle reflex (Hajcak \& Foti, 2008; Riesel et al., 2013). Errors committed in a social context are particularly distressing, especially for socially anxious individuals (Hewitt et al., 2003; Schlenker \& Leary, 1982), reflecting enhanced vigilance to perceived social threats. A number of studies have shown that socially anxious individuals exhibit enhanced attention and vigilance to social information, such as biases toward orienting to threatening facial expressions (Bar-Haim, Lamy, Pergamin, Bakermans-Kranenburg, van IJzendoorn, 2007; Mogg \& Bradley, 2002; Mogg, Philippot, \& Bradley, 2004;

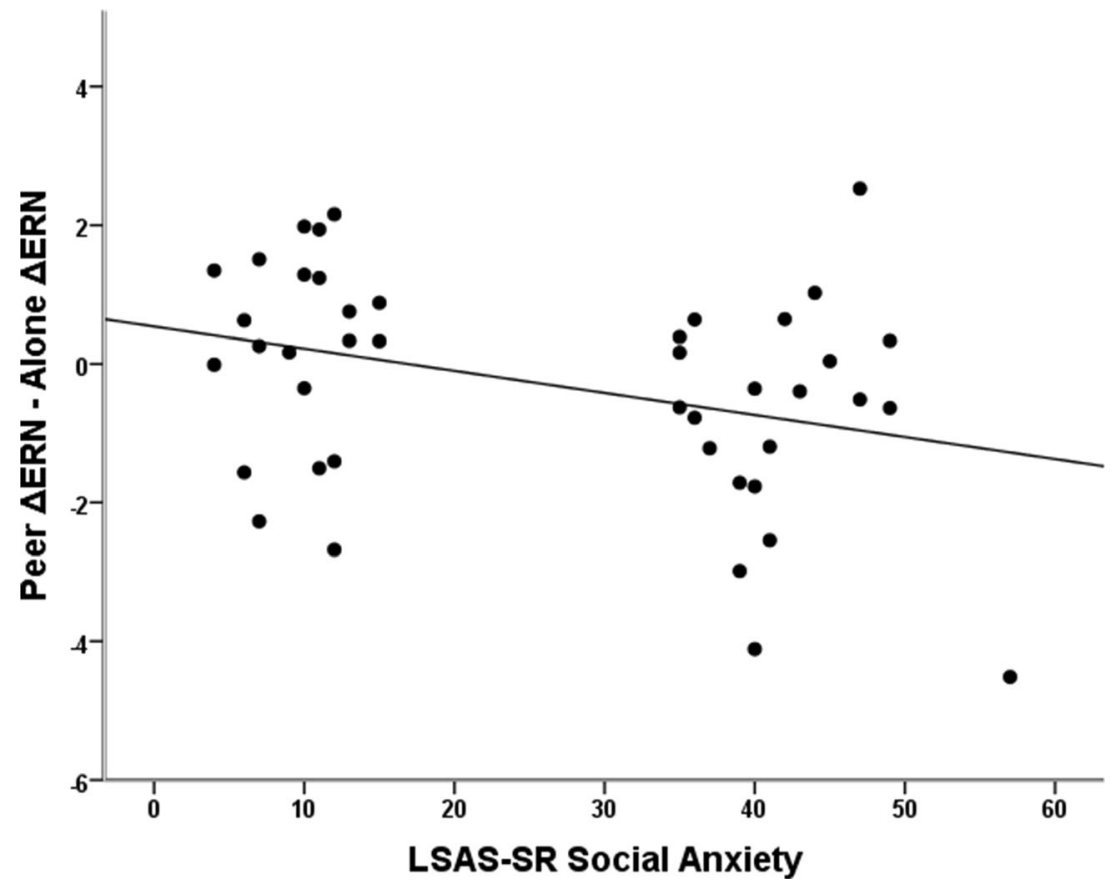

Fig. 3 Scatterplot depicting the relation between the Total Anxiety score of the LSAS-SR and the change in $\triangle E R N$ across the peer and alone conditions (Peer $\triangle E R N-$ Alone $\triangle E R N$ ). A negative value indicates a larger (i.e., more negative) $\triangle E R N$ in the peer condition than in the alone condition 
Pishyar, Harris, \& Menzies, 2004) and biases in interpreting social contexts as threatening (Amir, Beard, \& Bower, 2005; Constans, Penn, Ihen, \& Hope, 1999). Furthermore, social anxiety symptoms are reduced following training to avoid orienting toward social threats (Amir et al., 2009).

The present study adds to the growing literature finding that the ERN is sensitive to contextual factors (Hajcak et al., 2005; Kim et al., 2005; Van Meel \& Van Heijningen, 2010). In the present study, we found that the ERN was influenced by social contextual factors only among high socially anxious individuals. One likely reason that we did not observe enhanced ERNs in social contexts in both high and low socially anxious individuals is that we recruited participants who scored at the extremes in social anxiety, which maximized the role of individual differences in influencing the ERN. Other work has also suggested that individual differences moderate motivational influences of the ERN (Pailing \& Segalowitz, 2004). For example, Dikman and Allen (2000) compared the ERN in participants characterized as being high or low in socialization across conditions in which errors were punished or correct responses were rewarded. The authors found that low-socialized individuals exhibited a reduced ERN in the punishment condition relative to the reward condition, whereas high-socialized individuals demonstrated no differences between the conditions. Similarly, Riesel and colleagues (2012) found that the degree to which the ERN was enhanced when errors were punished was related to anxiety symptoms. Thus, the present findings extend such prior work specifically to individual-level and contextual social factors.

A large body of research has demonstrated that an enhanced ERN is characteristic of individuals with anxiety (Endrass et al., 2008; Gehring et al., 2000; Weinberg, Klein, \& Hajcak, 2012; Weinberg et al., 2010). However, in the present study, no differences in ERNs were observed between high and low socially anxious individuals in nonsocial contexts. In the one published study examining social anxiety and the ERN in adults, Endrass and colleagues (2014) found that both adults with SAD and adults with obsessive compulsive disorder demonstrated an enhanced ERN as compared to healthy comparisons. However, social anxiety symptoms were unrelated to the magnitude of the ERN, suggesting that other symptoms common to both disorders might explain the observed enhanced ERN. It has been suggested that the enhanced ERN observed among many anxiety disorders is driven by symptoms of general distress/anxious apprehension (Moser et al., 2012; Moser et al., 2013; Simons, 2010; Weinberg et al., 2010), which is a core symptom of most anxiety disorders (L. A. Clark \& Watson, 1991; Watson, 2005). Thus, future research should further explore whether social anxiety symptoms within clinical anxiety disorders are also related to the magnitude of the ERN.
The degree to which the ERN was enhanced in social contexts from nonsocial contexts (i.e., Peer $\triangle E R N$ - Alone $\triangle \mathrm{ERN}$ ) was most strongly associated with social anxiety symptoms, but also related to general anxiety symptoms. This finding is not surprising, given that social anxiety and general anxiety are highly correlated and comorbid (Grant et al., 2005; Mennin, Heimberg, \& Jack, 2000; Watson, 2005). We also observed a strong correlation between LSAS social anxiety and PSWQ general anxiety. Thus, it is difficult to determine whether the enhanced ERNs observed among socially anxious individuals in social contexts were primarily driven by social anxiety symptoms or by more general anxiety symptoms (i.e., worry). However, it is important to note that social concerns are one of the main worries reported by adults (Ladouceur, Freeston, Fournier, Dugas, \& Doucet, 2002), and that social worries are critical in the etiology of SAD (D. M. Clark \& Wells, 1995; Rapee \& Heimberg, 1997). Thus, many of the worries reported by highly socially anxious individuals may represent worries related to social factors. The PSWQ, our primary measure of anxious apprehension (i.e., general worry), does not differentiate social from nonsocial worries. Thus, it is difficult to resolve this issue in the present study. This issue of the specificity of the ERN and anxiety relation was recently examined by Zambrano-Vazquez and Allen (2014), who recruited high obsessive compulsive participants and high-worry participants and found that only the highworry participants exhibited an enhanced ERN. Future research on the specificity of the relation between social anxiety and the ERN is needed.

The ERN is a candidate biological endophenotype for anxiety disorders, mediating early genetic risk and the later development of anxiety (Gottesman \& Gould, 2003; Olvet \& Hajcak, 2008). The magnitude of the ERN is relatively stable within an individual though both childhood (Meyer, Bress, \& Proudfit, 2014) and adulthood (Olvet \& Hajcak, 2009; Weinberg \& Hajcak, 2011), and it is heritable (Anokhin, Golosheykin, \& Heath, 2008). Furthermore, an enhanced ERN is characteristic of individuals with a personal or family history of anxiety disorders (Carrasco, Harbin, et al., 2013; Carrasco, Hong, et al., 2013; Gehring et al., 2000; Riesel, Endrass, Kaufmann, \& Kathmann, 2011). The relation between anxiety and the ERN emerges in childhood (Carrasco, Harbin, et al., 2013; Ladouceur et al., 2006; A. Meyer et al., 2013; Meyer, Weinberg, Klein, \& Hajcak, 2012), suggesting that the ERN may reflect a biological marker of early dispositional responses to threat (Proudfit et al., 2013). Indeed, children characterized as being behaviorally inhibited, a temperament identified in early childhood and characterized by fear of novel social stimuli (Fox et al., 2001; Kagan, Reznick, Snidman, Gibbons, \& Johnson, 1988), demonstrate an enhanced ERN at 7 years of age (Lahat et al., 2014). However, little research has explored whether individual differences in temperament, such as behavioral inhibition, may interact with 
contextual factors in predicting the magnitude of the ERN. Brooker and Buss (2014) examined the ERN in temperamentally fearful children and found that harsh parenting moderated the relation between fearfulness at age 2 and the ERN at age 4 , such that there was a positive association between the ERN and fearfulness only among participants exposed to greater harsh parenting. Future studies should utilize similar contextual modulation procedures to determine whether an elevated ERN in social contexts may predict the emergence of later social anxiety symptoms among behaviorally inhibited children.

A number of limitations of the present study should be addressed. First, no information on psychiatric diagnoses was collected. Thus, it is unknown whether the participants in the present study met the diagnosis for SAD or any other psychiatric disorders, or whether the high socially anxious group were representative of patients with SAD. Using the LSAS total score, a clinical cutoff of 60 or above has been suggested to represent high probability of a SAD diagnosis (Mennin et al., 2002). In the present study, 21 out of the 22 participants in the high socially anxious group scored above this cutoff, whereas no participants reached this cutoff in the low socially anxious group. In addition, we did not collect any information on medication status or brain injury, which are factors known to influence the ERN (de Bruijn, Sabbe, Hulstijn, Ruigt, \& Verkes, 2006; Swick \& Turken, 2002), thus making it unknown whether such variables influenced the present findings. Future studies should utilize a similar social manipulation procedure in patients with SAD and in healthy comparisons, as well as collect more extensive information on medication use and neurological impairments.

It is also important to note that although we found that the ERN was robustly modulated by social motivational factors among high socially anxious individuals, it is unknown whether socially anxious individuals perceived errors that occurred during social observation and evaluation as being more socially threatening or anxiety inducing than did the low socially anxious individuals. Thus, it is difficult to know whether the enhanced ERN in social contexts among high socially anxious individuals was due to enhanced social motivation, anxious arousal, worry, or some other factor. Future research should document state changes in motivation and anxiety across different contexts to better delineate the psychological mechanisms that enhance the ERN. Finally, because we matched the confederate to the gender of the participant, we were unable to explore the effect of gender in influencing the ERN. Although the social anxiety symptoms reported during opposite-gender and same-gender interactions are highly correlated (Robins, 1986), there is evidence that opposite-gender situations may cause greater physiological arousal among both socially anxious adults and healthy controls (Turner, Beidel, \& Larkin, 1986). Thus, the enhancement to the ERN in social contexts might be greater during opposite-gender social observation and evaluation. Future research should explore this possibility.

In sum, in the present study we investigated whether highly socially anxious individuals exhibit differences in error monitoring, as measured by the ERN and related ERP components, across social and nonsocial contexts, as compared to less socially anxious individuals. Our findings revealed that socially anxious individuals exhibited an enhanced ERN when errors were committed during social-evaluative contexts, as compared to when errors committed alone. No differences were observed between social and nonsocial contexts for less socially anxious individuals. Furthermore, individual differences in social anxiety were related to the degree to which the ERN was elevated in social relative to nonsocial contexts. These findings suggest that social anxiety is characterized by an enhanced ERN during the observation and evaluation of errors, which is suggestive of enhanced defensive reactivity and vigilance to social situations.

Author Note This research was partially supported by the National Institutes of Health (Grant Nos. HDR3717899, to N.A.F., and 5T32HD007542, to Melanie Killen). D.S.P. is supported by the NIMHIntramural Research Program. The authors declare no competing financial interests.

\section{References}

Amir, N., Beard, C., Taylor, C. T., Klumpp, H., Elias, J., Burns, M., \& Chen, X. (2009). Attention training in individuals with generalized social phobia: A randomized controlled trial. Journal of Consulting and Clinical Psychology, 77, 961-973. doi:10.1037/a0016685

Amir, N., Beard, C., \& Bower, E. (2005). Interpretation bias and social anxiety. Cognitive Therapy and Research, 29, 433-443. doi:10. 1007/s10608-005-2834-5

Amir, N., Klumpp, H., Elias, J., Bedwell, J. S., Yanasak, N., \& Miller, L. S. (2005). Increased activation of the anterior cingulate cortex during processing of disgust faces in individuals with social phobia. Biological Psychiatry, 57, 975-981. doi:10.1016/j.biopsych.2005. 01.044

Amodio, D. M., Master, S. L., Yee, C. M., \& Taylor, S. E. (2008). Neurocognitive components of the behavioral inhibition and activation systems: Implications for theories of self-regulation. Psychophysiology, 45, 11-19. doi:10.1111/j.1469-8986.2007. 00609.x

Anokhin, A. P., Golosheykin, S., \& Heath, A. C. (2008). Heritability of frontal brain function related to action monitoring. Psychophysiology, 45, 524-534. doi:10.1111/j.1469-8986.2008. 00664.x

Bar-Haim, Y., Lamy, D., Pergamin, L., Bakermans-Kranenburg, M. J., van IJzendoorn, M. H. (2007). Threat-related attentional bias in anxious and nonanxious individuals: A meta-analytic study. Psychological Bulletin, 133, 1-24. doi:10.1037/0033-2909.133.1.1

Beck, A. T., Steer, R. A., Ball, R., \& Ranieri, W. F. (1996). Comparison of Beck Depression Inventories-IA and-II in psychiatric outpatients. Journal of Personality Assessment, 67, 588-597. doi:10.1207/ s15327752jpa6703_13 
Beidel, D. C., Turner, S. M., \& Dancu, C. V. (1985). Physiological, cognitive and behavioral aspects of social anxiety. Behaviour Research and Therapy, 23, 109-117. doi:10.1016/0005-7967(85) 90019-1

Brooker, R. J., \& Buss, K. A. (2014). Toddler fearfulness is linked to individual differences in error-related negativity during preschool. Developmental Neuropsychology, 39, 1-8. doi:10.1080/87565641. 2013.826661

Brown, T. A., Antony, M. M., \& Barlow, D. H. (1992). Psychometric properties of the Penn State Worry Questionnaire in a clinical anxiety disorders sample. Behaviour Research and Therapy, 30, 33-37. doi:10.1016/0005-7967(92)90093-V

Bumberry, W., Oliver, M. J., \& McClure, J. N. (1978). Validation of the Beck Depression Inventory in a university population using psychiatric estimate as the criterion. Journal of Consulting and Clinical Psychology, 46, 150-155. doi:10.1037/0022-006X.46.1.150

Carrasco, M., Harbin, S. M., Nienhuis, J. K., Fitzgerald, K. D., Gehring, W. J., \& Hanna, G. L. (2013). Increased error-related brain activity in youth with obsessive-compulsive disorder and unaffected siblings. Depression and Anxiety, 30, 39-46. doi:10.1002/da.22035

Carrasco, M., Hong, C., Nienhuis, J. K., Harbin, S. M., Fitzgerald, K. D., Gehring, W. J., \& Hanna, G. L. (2013). Increased error-related brain activity in youth with obsessive-compulsive disorder and other anxiety disorders. Neuroscience Letters, 541, 214-218. doi:10.1016/j. neulet.2013.02.017

Clark, L. A., \& Watson, D. (1991). Tripartite model of anxiety and depression: Psychometric evidence and taxonomic implications. Journal of Abnormal Psychology, 100, 316-336. doi:10.1037/ 0021-843X.100.3.316

Clark, D. M., \& Wells, A. (1995). A cognitive model of social phobia. In R. G. Heimberg, M. R. Liebowitz, D. A. Hope, \& F. R. Schneier (Eds.), Social phobia: Diagnosis, assessment, and treatment (pp. 69-93). New York, NY: Guilford Press.

Constans, J. I., Penn, D. L., Ihen, G. H., \& Hope, D. A. (1999). Interpretive biases for ambiguous stimuli in social anxiety. Behaviour Research and Therapy, 37, 643-651. doi:10.1016/ S0005-7967(98)00180-6

Cornwell, B. R., Johnson, L., Berardi, L., \& Grillon, C. (2006). Anticipation of public speaking in virtual reality reveals a relationship between trait social anxiety and startle reactivity. Biological Psychiatry, 59, 664-666. doi:10.1016/j.biopsych.2005.09.015

Critchley, H. D., Tang, J., Glaser, D., Butterworth, B., \& Dolan, R. J. (2005). Anterior cingulate activity during error and autonomic response. NeuroImage, 27, 885-895. doi:10.1016/j.neuroimage. 2005. 05.047

Davey, G. C. L. (1993). A comparison of three worry questionnaires. Behaviour Research and Therapy, 31, 51-56. doi:10.1016/00057967(93)90042-S

De Bruijn, E. R. A., Sabbe, B. G. C., Hulstijn, W., Ruigt, G. S. F., \& Verkes, R. J. (2006). Effects of antipsychotic and antidepressant drugs on action monitoring in healthy volunteers. Brain Research, 1105, 122-129. doi:10.1016/j.brainres.2006.01.006

Dehaene, S., Posner, M. I., \& Tucker, D. M. (1994). Localization of a neural system for error detection and compensation. Psychological Science, 5, 303-305. doi:10.1111/j.1467-9280.1994.tb00630.x

Delorme, A., \& Makeig, S. (2004). EEGLAB: An open source toolbox for analysis of single-trial EEG dynamics including independent component analysis. Journal of Neuroscience Methods, 134, 9-21. doi:10.1016/j.jneumeth.2003.10.009

Dien, J. (2010). The ERP PCA toolkit: An open source program for advanced statistical analysis of event-related potential data. Journal of Neuroscience Methods, 187, 138-145. doi:10.1016/j. jneumeth.2009.12.009

Dikman, Z. V., \& Allen, J. J. B. (2000). Error monitoring during reward and avoidance learning in high- and low-socialized individuals. Psychophysiology, 37, 43-54. doi:10.1111/1469-8986.3710043
Endrass, T., Klawohn, J., Schuster, F., \& Kathmann, N. (2008). Overactive performance monitoring in obsessive-compulsive disorder: ERP evidence from correct and erroneous reactions. Neuropsychologia, 46, 1877-1887. doi:10.1016/j. neuropsychologia.2007.12.001

Endrass, T., Riesel, A., Kathmann, N., \& Buhlmann, U. (2014). Performance monitoring in obsessive-compulsive disorder and social anxiety disorder. Journal of Abnormal Psychology, 123, 705714. doi:10.1037/abn0000012

Eriksen, B. A., \& Eriksen, C. W. (1974). Effects of noise letters upon the identification of a target letter in a nonsearch task. Perception \& Psychophysics, 16, 143-149. doi:10.3758/BF03203267

Falkenstein, M., Hohnsbein, J., Hoormann, J., \& Blanke, L. (1991). Effects of crossmodal divided attention on late ERP components: II. Error processing in choice reaction tasks. Electroencephalography and Clinical Neurophysiology, 78, 447455. doi:10.1016/0013-4694(91)90062-9

Ford, J. M. (1999). Schizophrenia: The broken P300 and beyond. Psychophysiology, 36, 667-682. doi:10.1111/1469-8986.3660667

Fox, A. N., Henderson, H. A., Rubin, K. H., Calkins, S. D., \& Schmidt, L. A. (2001). Continuity and discontinuity of behavioral inhibition and exuberance: Psychophysiological and behavioral influences across the first four years of life. Child Development, 72, 1-21. doi:10. 1111/1467-8624.00262

Fresco, D. M., Coles, M. E., Heimberg, R. G., Liebowitz, M. R., Hami, S., Stein, M. B., \& Goetz, D. (2001). The Liebowitz Social Anxiety Scale: A comparison of the psychometric properties of self-report and clinician-administered formats. Psychological Medicine, 31, 1025-1035. doi:10.1017/S0033291701004056

Furlan, P. M., DeMartinis, N., Schweizer, E., Rickels, K., \& Lucki, I. (2001). Abnormal salivary cortisol levels in social phobic patients in response to acute psychological but not physical stress. Biological Psychiatry, 50, 254-259. doi:10.1016/S0006-3223(00)01126-4

Ganushchak, L. Y., \& Schiller, N. O. (2008). Motivation and semantic context affect brain error-monitoring activity: An event-related brain potentials study. NeuroImage, 39, 395-405. doi:10.1016/j. neuroimage.2007.09.001

Geen, R. G. (1991). Social motivation. Annual Review of Psychology, 42, 377-399. doi:10.1146/annurev.ps.42.020191.002113

Gehring, W. J., Goss, B., Coles, M. G. H., Meyer, D. E., \& Donchin, E. (1993). A neural system for error detection and compensation. Psychological Science, 4, 385-390. doi:10.1111/j.1467-9280.1993. tb00586.x

Gehring, W. J., Himle, J., \& Nisenson, L. G. (2000). Action-monitoring dysfunction in obsessive-compulsive disorder. Psychological Science, 11, 1-6. doi:10.1111/1467-9280.00206

Gehring, W. J., \& Knight, R. T. (2000). Prefrontal-cingulate interactions in action monitoring. Nature Neuroscience, 3, 516-520. doi:10. $1038 / 74899$

Gillis, M. M., Haaga, D. A. F., \& Ford, G. T. (1995). Normative values for the Beck Anxiety Inventory, Fear Questionnaire, Penn State Worry Questionnaire, and Social Phobia and Anxiety Inventory. Psychological Assessment, 7, 450-455. doi:10.1037/1040-3590.7. 4.450

Gottesman, I. I., \& Gould, T. D. (2003). The endophenotype concept in psychiatry: Etymology and strategic intentions. American Journal of Psychiatry, 160, 636-645. doi:10.1176/appi.ajp.160.4.636

Grant, B. F., Hasin, D. S., Blanco, C., Stinson, F. S., Patricia, S., Goldstein, R. B., ... Huang, B. (2005). The epidemiology of social anxiety disorder in the United States: Results from the national epidemiologic survey on alcohol and related conditions. Journal of Clinical Psychiatry, 66, 1351-1361. doi:10.4088/JCP.v66n1102

Grillon, C. (2002). Startle reactivity and anxiety disorders: Aversive conditioning, context, and neurobiology. Biological Psychiatry, 52, 958-975. doi:10.1016/S0006-3223(02)01665-7 
Hajcak, G. (2012). What we've learned from mistakes insights from error-related brain activity. Current Directions in Psychological Science, 21, 101-106. doi:10.1177/0963721412436809

Hajcak, G., \& Foti, D. (2008). Errors are aversive: Defensive motivation and the error-related negativity. Psychological Science, 19, 103 108. doi:10.1111/j.1467-9280.2008.02053.x

Hajcak, G., McDonald, N., \& Simons, R. F. (2003a). Anxiety and errorrelated brain activity. Biological Psychology, 64, 77-90. doi:10. 1016/S0301-0511(03)00103-0

Hajcak, G., McDonald, N., \& Simons, R. F. (2003b). To err is autonomic: Error-related brain potentials, ANS activity, and post-error compensatory behavior. Psychophysiology, 40, 895-903. doi:10.1111/14698986.00107

Hajcak, G., McDonald, N., \& Simons, R. F. (2004). Error-related psychophysiology and negative affect. Brain and Cognition, 56, 189197. doi:10.1016/j.bandc.2003.11.001

Hajcak, G., Moser, J. S., Yeung, N., \& Simons, R. F. (2005). On the ERN and the significance of errors. Psychophysiology, 42, 151-160. doi: 10.1111/j.1469-8986.2005.00270.x

Heimberg, R. G., Horner, K. J., Juster, H. R., Safren, S. A., Brown, E. J., Schneier, F. R., \& Liebowitz, M. R. (1999). Psychometric properties of the Liebowitz Social Anxiety Scale. Psychological Medicine, 29, 199-212.

Hewitt, P. L., Flett, G. L., Sherry, S. B., Habke, M., Parkin, M., Lam, R. W., ... Stein, M. B. (2003). The interpersonal expression of perfection: Perfectionistic self-presentation and psychological distress. Journal of Personality and Social Psychology, 84, 1303-1325. doi:10.1037/0022-3514.84.6.1303

Holroyd, C. B., Dien, J., \& Coles, M. G. H. (1998). Error-related scalp potentials elicited by hand and foot movements: Evidence for an output-independent error-processing system in humans. Neuroscience Letters, 242, 65-68. doi:10.1016/S0304-3940(98) 00035-4

Kagan, J., Reznick, J. S., Snidman, N., Gibbons, J., \& Johnson, M. O. (1988). Childhood derivatives of inhibition and lack of inhibition to the unfamiliar. Child Development, 59, 1580. doi:10.2307/1130672

Keselman, H. J., Wilcox, R. R., \& Lix, L. M. (2003). A generally robust approach to hypothesis testing in independent and correlated groups designs. Psychophysiology, 40, 586-596. doi:10.1111/1469-8986. 00060

Kessler, R. C., Berglund, P., Demler, O., Jin, R., Merikangas, K. R., \& Walters, E. E. (2005). Lifetime prevalence and age-of-onset distributions of DSM-IV disorders in the National Comorbidity Survey Replication. Archives of General Psychiatry, 62, 593-602. doi:10. 1001/archpsyc.62.6.593

Kim, E. Y., Iwaki, N., Uno, H., \& Fujita, T. (2005). Error-related negativity in children: Effect of an observer. Developmental Neuropsychology, 28, 871-883. doi:10.1207/s15326942dn2803 7

Ladouceur, C. D., Dahl, R. E., Birmaher, B., Axelson, D. A., \& Ryan, N. D. (2006). Increased error-related negativity (ERN) in childhood anxiety disorders: ERP and source localization. Journal of Child Psychology and Psychiatry, 47, 1073-1082. doi:10.1111/j.14697610.2006.01654.x

Ladouceur, R., Freeston, M. H., Fournier, S., Dugas, M. J., \& Doucet, C. (2002). The social basis of worry in three samples: high-school students, university students, and older adults. Behavioural and Cognitive Psychotherapy, 30, 427-438. doi:10.1017/ S1352465802004046

Lahat, A., Lamm, C., Chronis-Tuscano, A., Pine, D. S., Henderson, H. A., \& Fox, N. A. (2014). Early behavioral inhibition and increased error monitoring predict later social phobia symptoms in childhood. Journal of the American Academy of Child \& Adolescent Psychiatry, 53, 447-455. doi:10.1016/j.jaac.2013.12.019

Landis, C., Hunt, W. A., \& Strauss, H. (1939). The startle pattern. New York, NY: Farrar \& Rinehart.
Larson, M. J., Baldwin, S. A., Good, D. A., \& Fair, J. E. (2010). Temporal stability of the error-related negativity (ERN) and post-error positivity (Pe): The role of number of trials. Psychophysiology, 47, 11671171. doi:10.1111/j.1469-8986.2010.01022.x

Levin, A. P., Saoud, J. B., Strauman, T., Gorman, J. M., Fyer, A. J., Crawford, R., \& Liebowitz, M. R. (1993). Responses of "generalized" and "discrete" social phobics during public speaking. Journal of Anxiety Disorders, 7, 207-221. doi:10.1016/08876185(93)90003-4

Liebowitz, M. R. (1987). Social phobia. Modern Problems of Pharmacopsychiatry, 22, 141-173.

Lorberbaum, J. P., Kose, S., Johnson, M. R., Arana, G. W., Sullivan, L. K., Hamner, M. B., ... George, M. S. (2004). Neural correlates of speech anticipatory anxiety in generalized social phobia. Neuroreport, 15, 2701-2705.

Luu, P., Collins, P., \& Tucker, D. M. (2000). Mood, personality, and selfmonitoring: Negative affect and emotionality in relation to frontal lobe mechanisms of error monitoring. Journal of Experimental Psychology: General, 129, 43-60. doi:10.1037/0096-3445.129.1.43

Mauss, I., Wilhelm, F., \& Gross, J. (2004). Is there less to social anxiety than meets the eye? Emotion experience, expression, and bodily responding. Cognition and Emotion, 18, 631-642. doi:10.1080/ 02699930341000112

McDermott, J. M., Perez-Edgar, K., Henderson, H. A., Chronis-Tuscano, A., Pine, D. S., \& Fox, N. A. (2009). A history of childhood behavioral inhibition and enhanced response monitoring in adolescence are linked to clinical anxiety. Biological Psychiatry, 65, 445-448. doi:10.1016/j.biopsych.2008.10.043

Mennin, D. S., Fresco, D. M., Heimberg, R. G., Schneier, F. R., Davies, S. O., \& Liebowitz, M. R. (2002). Screening for social anxiety disorder in the clinical setting: Using the Liebowitz Social Anxiety Scale. Journal of Anxiety Disorders, 16, 661-673. doi:10.1016/S08876185(02)00134-2

Mennin, D. S., Heimberg, R. G., \& Jack, M. S. (2000). Comorbid generalized anxiety disorder in primary social phobia: Symptom severity, functional impairment, and treatment response. Journal of Anxiety Disorders, 14, 325-343. doi:10.1016/S0887-6185(00) 00026-8

Meyer, A., Bress, J. N., \& Proudfit, G. H. (2014). Psychometric properties of the error-related negativity in children and adolescents. Psychophysiology, 51, 602-610. doi:10.1111/psyp.12208

Meyer, A., Hajcak, G., Torpey, D. C., Kujawa, A., Kim, J., Bufferd, S., ... Klein, D. N. (2013). Increased error-related brain activity in sixyear-old children with clinical anxiety. Journal of Abnormal Child Psychology, 41, 1257-1266. doi:10.1007/s10802-013-9762-8

Meyer, T. J., Miller, M. L., Metzger, R. L., \& Borkovec, T. D. (1990). Development and validation of the Penn State Worry Questionnaire. Behaviour Research and Therapy, 28, 487-495. doi:10.1016/00057967(90)90135-6

Meyer, A., Weinberg, A., Klein, D. N., \& Hajcak, G. (2012). The development of the error-related negativity $(\mathrm{ERN})$ and its relationship with anxiety: Evidence from 8 to 13 year-olds. Developmental Cognitive Neuroscience, 2, 152-161. doi:10.1016/j.den.2011.09. 005

Mogg, K., \& Bradley, B. P. (2002). Selective orienting of attention to masked threat faces in social anxiety. Behaviour Research and Therapy, 40, 1403-1414. doi:10.1016/S0005-7967(02)00017-7

Mogg, K., Philippot, P., \& Bradley, B. P. (2004). Selective attention to angry faces in clinical social phobia. Journal of Abnormal Psychology, 113, 160-165. doi:10.1037/0021-843X.113.1.160

Moser, J. S., Moran, T. P., Schroder, H. S., Donnellan, M. B., \& Yeung, N. (2013). On the relationship between anxiety and error monitoring: A meta-analysis and conceptual framework. Frontiers in Human Neuroscience, 7, 466. doi:10.3389/fnhum.2013.00466

Moser, J. S., Moran, T. P., \& Jendrusina, A. A. (2012). Parsing relationships between dimensions of anxiety and action monitoring brain 
potentials in female undergraduates. Psychophysiology, 49, 3-10. doi:10.1111/j.1469-8986.2011.01279.x

Olvet, D. M., \& Hajcak, G. (2008). The error-related negativity (ERN) and psychopathology: Toward an endophenotype. Clinical Psychology Review, 28, 1343-1354. doi:10.1016/j.cpr.2008.07.003

Olvet, D. M., \& Hajcak, G. (2009). Reliability of error-related brain activity. Brain Research, 1284, 89-99. doi:10.1016/j.brainres. 2009.05.079

Pailing, P. E., \& Segalowitz, S. J. (2004). The error-related negativity as a state and trait measure: Motivation, personality, and ERPs in response to errors. Psychophysiology, 41, 84-95. doi:10.1111/14698986.00124

Pishyar, R., Harris, L. M., \& Menzies, R. G. (2004). Attentional bias for words and faces in social anxiety. Anxiety, Stress \& Coping, 17, 2336. doi:10.1080/10615800310001601458

Perrin, F., Pernier, J., Bertrand, O., \& Echallier, J. F. (1989). Spherical splines for scalp potential and current density mapping. Electroencephalography and Clinical Neurophysiology, 72, 184187. doi:10.1016/0013-4694(89)90180-6

Perrin, F., Pernier, J., Bertrand, O., \& Echallier, J. F. (1990). Corrigenda: EEG 02274,Electroencephalography and Clinical Neurophysiology, 76, 565. doi:10.1016/0013-4694(90)90009-9

Proudfit, G. H., Inzlicht, M., \& Mennin, D. S. (2013). Anxiety and error monitoring: The importance of motivation and emotion. Frontiers in Human Neuroscience, 7, 636. doi:10.3389/fnhum.2013.00636

Rapee, R. M., \& Heimberg, R. G. (1997). A cognitive-behavioral model of anxiety in social phobia. Behaviour Research and Therapy, 35, 741-756. doi:10.1016/S0005-7967(97)00022-3

Rapee, R. M., \& Spence, S. H. (2004). The etiology of social phobia: Empirical evidence and an initial model. Clinical Psychology Review, 24, 737-767. doi:10.1016/j.cpr.2004.06.004

Riesel, A., Endrass, T., Kaufmann, C., \& Kathmann, N. (2011). Overactive error-related brain activity as a candidate endophenotype for obsessive-compulsive disorder: Evidence from unaffected firstdegree relatives. The American Journal of Psychiatry, 168, 317 324. doi:10.1176/appi.ajp.2010.10030416

Riesel, A., Weinberg, A., Endrass, T., Kathmann, N., \& Hajcak, G. (2012). Punishment has a lasting impact on error-related brain activity. Psychophysiology, 49, 239-247. doi:10.1111/j.1469-8986. 2011.01298.x

Riesel, A., Weinberg, A., Moran, T., \& Hajcak, G. (2013). Time course of error-potentiated startle and its relationship to error-related brain activity. Journal of Psychophysiology, 27, 51-59. doi:10.1027/ 0269-8803/a000093

Robins, C. J. (1986). Sex role perceptions and social anxiety in oppositesex and same-sex situations. Sex Roles, 14, 383-395. doi:10.1007/ BF00288423

Scheffers, M. K., \& Coles, M. G. H. (2000). Performance monitoring in a confusing world: Error-related brain activity, judgments of response accuracy, and types of errors. Journal of Experimental Psychology: Human Perception and Performance, 26, 141-151. doi:10.1037/ 0096-1523.26.1.141

Schlenker, B. R., \& Leary, M. R. (1982). Social anxiety and self-presentation: A conceptualization model. Psychological Bulletin, 92, 641669. doi:10.1037/0033-2909.92.3.641

Simons, R. F. (2010). The way of our errors: Theme and variations. Psychophysiology, 47, 1-14. doi:10.1111/j.1469-8986. 2009.00929.x

Swick, D., \& Turken, A. U. (2002). Dissociation between conflict detection and error monitoring in the human anterior cingulate cortex. Proceedings of the National Academy of Sciences, 99, 16354 16359. doi:10.1073/pnas.252521499

Turner, S. M., Beidel, D. C., \& Larkin, K. T. (1986). Situational determinants of social anxiety in clinic and nonclinic samples: Physiological and cognitive correlates. Journal of Consulting and Clinical Psychology, 54, 523-527. doi:10.1037/0022-006X.54.4.523

Van Meel, C. S., \& Van Heijningen, C. A. A. (2010). The effect of interpersonal competition on monitoring internal and external error feedback. Psychophysiology, 47, 213-222. doi:10.1111/j.14698986.2009.00944.x

Van Veen, V., \& Carter, C. S. (2002). The timing of action-monitoring processes in the anterior cingulate cortex. Journal of Cognitive Neuroscience, 14, 593-602. doi:10.1162/08989290260045837

Vidal, F., Burle, B., Bonnet, M., Grapperon, J., \& Hasbroucq, T. (2003). Error negativity on correct trials: A reexamination of available data. Biological Psychology, 64, 265-282. doi:10.1016/S0301-0511(03) 00097-8

Vidal, F., Hasbroucq, T., Grapperon, J., \& Bonnet, M. (2000). Is the "error negativity" specific to errors? Biological Psychology, 51, 109-128. doi:10.1016/S0301-0511(99)00032-0

Watson, D. (2005). Rethinking the mood and anxiety disorders: A quantitative hierarchical model for DSM-V. Journal of Abnormal Psychology, 114, 522. doi:10.1037/0021-843X.114.4.522

Weinberg, A., \& Hajcak, G. (2011). Longer term test-retest reliability of error-related brain activity. Psychophysiology, 48, 1420-1425. doi: 10.1111/j.1469-8986.2011.01206.x

Weinberg, A., Klein, D. N., \& Hajcak, G. (2012). Increased error-related brain activity distinguishes generalized anxiety disorder with and without comorbid major depressive disorder. Journal of Abnormal Psychology, 121, 885-896. doi:10.1037/a0028270

Weinberg, A., Olvet, D. M., \& Hajcak, G. (2010). Increased error-related brain activity in generalized anxiety disorder. Biological Psychology, 85, 472-480. doi:10.1016/j.biopsycho.2010.09.011

Zambrano-Vazquez, L., \& Allen, J. J. B. (2014). Differential contributions of worry, anxiety, and obsessive compulsive symptoms to ERN amplitudes in response monitoring and reinforcement learning tasks. Neuropsychologia, 61, 197-209. doi:10.1016/j. neuropsychologia.2014.06.023 